\title{
MMP1 is a Promiseful Prognostic Biomarker and Correlating with Immune Infiltrates in Hepatocellular Carcinoma
}

Lei Dai ( $\nabla$ dl2006love@163.com )

Lihuili hospital https://orcid.org/0000-0001-5742-1963

Joseph Muggnyi

Lihuili hospital

xingchen cai

Lihuili hospital

shuqi mao

Lihuili hospital

tongyue zhang

Tongji Medical University: Huazhong University of Science and Technology Tongji Medical College

haihong shi

Lihuili hospital

caide lu

Lihuilihosiptal

changjiang lu

Ningbo Medical Treatment Centre Li Huili Hospital

\section{Research Article}

Keywords: MMP1, prognosis, biomarker, immune infiltration, hepatocellular carcinoma

Posted Date: June 1st, 2021

DOI: https://doi.org/10.21203/rs.3.rs-547264/v1

License: @) (7) This work is licensed under a Creative Commons Attribution 4.0 International License. Read Full License 


\section{Abstract}

Background: Recombinase-aided amplification(RAA) is a new, simple, and ultrafast isothermal molecular diagnostic technique performed within 30 min at $39^{\circ} \mathrm{C}-42^{\circ} \mathrm{C}$.In this study, we evaluated the clinical performance of four duplex RAA kits for hepatitis B virus(HBV), human adenovirus $3(\mathrm{HAdV} 3)$, human adenovirus 7(HAdV7), and Bordetella pertussis and one duplex reverse-transcription RAA (RT-RAA) kit for respiratory syncytial virus (RSV).

Methods: A total of 392 sera and 374 respiratory tract samples were collected from five institutions in four China regions. Each RAA kit's sensitivity and specificity were compared with those of real-time quantitative polymerase chain reaction(qPCR),real-time quantitative reverse-transcription polymerase chain reaction(qRT-PCR), or sequencing.

Results: Compared with qPCR or qRT-PCR, the sensitivities of HBV RAA,RSV RT-RAA, and B.pertussis RAA were $97.55 \%, 96.67 \%$, and $100 \%$,respectively,and all of the specificities were $100 \%$. The total coincidence rates were $97.78 \%(383 / 392,95 \% \mathrm{Cl}: 95.63 \%-98.85 \%), 97.70 \%(212 / 217,95 \% \mathrm{Cl}$ :94.57\%-99.16\%), and 100\% $(60 / 60,95 \% \mathrm{Cl}: 92.80 \%-100 \%)$,respectively. The Kappa values were $0.977,0.947$, and 1 ,respectively $(\mathrm{P}<0.05)$. Regarding the sequencing, the sensitivities of HAdV3 RAA and HAdV7 RAA were $100 \%$ and $97.37 \%$, respectively, and all specificities were $100 \%$. The total coincidence rates were $100 \%$ (97/97,95\% Cl:91.58\%-100\%) and 98.97\%(96/97,95\% Cl:94.39\%-99.82\%), and the Kappa values were 1 and 0.978 (P<0.05),respectively.

Conclusions: With comparable clinical performance, these RAA kits are suitable assays for rapidly detecting pathogens in resource-limited laboratories.

\section{Introduction}

Hepatocellular carcinoma ( $\mathrm{HCC}$ ), remains the third leading cause of tumor-related death worldwide ${ }^{[1]}$ and a significant health burden across the board. Chronic viral hepatitis $\mathrm{B}$ induced cirrhosis leading to $\mathrm{HCC}$ is the most common progress pattern in liver cancer. The top three risk factors for HCC are alcohol consumption, chronic viral hepatitis $\mathrm{C}$ and non-alcoholic fatty liver disease ${ }^{[2]}$. Although great strides have been made in advancing early diagnosis, surgical technology ${ }^{[3]}$, targeted treatment ${ }^{[4,5]}$ and immune therapy ${ }^{[6,7]}$, high rate of recurrence and mortality remain a challenge due to most patients presenting with unresectable lesions or distant metastasis at time diagnosis, leading to a poor prognosis: a 5 -year overall survival rate of only $10-18 \%$ [8-10].

Matrix metalloproteinases (MMPs), a family of zinc-dependent endoproteases, is significantly related with extracellular matrix degradation by destroying diverse structure proteins, which plays a vital role in apoptosis, angiogenesis, and immune response ${ }^{[11-13]}$ of the tumor microenvironment. Notably, MMP-2, alongside MMP-9, are well known as the most common progression markers correlated with various tumor invasion and metastasis, especially in HCC ${ }^{[14,15]}$. Although MMP1 has been more commonly reported to be expressed in normal liver tissues ${ }^{[16]}$, it has also demonstrated an elevated capacity of invasion and migration in HCC by extracellular matrix (ECM) degradation in the epithelial-mesenchymal transition (EMT) ${ }^{[17]}$. MMP1 can be expressed in a wide range of cells including stromal fibroblasts, macrophages, endothelial cells and epithelial cells, having a low positive rate under normal conditions. However, it's expression can be elevated in malignant tumors with poor prognosis in various cancers (ovarian, liver, lung, gastric, colorectal, and prostate) ${ }^{[18-23]}$. While some studies have reported the interrelation between MMP1 and HCC, its distinct role in prognosis and the associated tumor-immunity are still unclear. Additionally, tumor infiltration immune cells (TIICs) and tumor-associated immune microenvironment are key areas of interest of current research ${ }^{[24,25]}$. Immune cells may respond to the tumor progression and metastasis through a multitude of pathways and interactions in HCC. The suppression of HCC immune microenvironment facilitates immune tolerance and escape by variant mechanisms ${ }^{[26]}$. MMPs play an important role in bladder cancer metastasis promotion through the B cell induced signaling pathway ${ }^{[27]}$ and their upregulation by tumor-associated macrophages contributes to tumor infiltration and metastasis in various carcinomas ${ }^{[28-30]}$, indicating their potential functions in tumor-immunity microenvironment. However, what and how MMP1 influences the immune cells and tumor-associated microenvironment still needs exploration.

This research was carried out to investigate the prognostic potential of MMP1 and its relationship with TIICs' biomarkers in HCC. Several online bioinformation analysis tools of public databases were used to examine the MMP1 expression levels (Oncomine and Tumor Immune Estimation Resource (TIMER) databases) and assess its prognostic potential (Kaplan-Meier plotter and Gene Expression Profiling Interactive Analysis (GEPIA) databases), along with the correlation between MMP1 and TIIC biomarkers (TIMER). We demonstrated that MMP1 may be a major independent predictor of prognosis of HCC and revealed the latent interrelationship and mechanism between MMP1 and TIIC biomarkers in patients with HCC.

\section{Materials And Methods \\ Oncomine Database Based Analysis}

Oncomine (https://www.oncomine.org) is currently the world's largest database of oncogene chip and features an integrated data mining platform, designed to mine cancer gene information. Oncomine, which integrates RNA and DNA-seq data from GEO, TCGA and published literature sources, has the most comprehensive profile of cancer mutations, gene expression data and related clinical information that can be used to identify new biomarkers or therapeutic targets $^{[31]}$. In our study, the MMP1 gene was selected and its expression levels were analyzed in tumor and normal tissues using the Oncomine database. The difference in results was considered statistically significant for $p$-value $<0.05$, with fold change $>1.5$. The threshold value of gene rank was set to "top $10 \%$ " and data type to "all".

\section{Kaplan-Meier Plotter Database Analysis}

The Kaplan-Meier Plotter database (http://kmplot.com/analysis) was constructed based on gene microarray and RNA-seq data from GEO, EGA, and TCGA public databases, and assessed the effect of 54,675 genes on survival rate in 21 cancer types $^{\text {[32] }}$. In order to investigate the relationship between MMP1 
expression and the prognosis of patients with liver, breast, ovarian, lung and gastric cancers, Kaplan-Meier Plotter database was utilized to do the Cox regression analysis and hazard ratios (HRs) and p-values from a log-rank test. The parameters were as follow: Affy id/Gene symbol: MMP1; patients split by auto-select best cutoff; HR: yes; $95 \%$ confidence interval (Cl): yes; with the remaining settings set to their default values.

\section{GEPIA Database Analysis}

GEPIA database (http://gepia.cancer-pku.cn/index.html), a public web server for tumor and normal gene expression profiling and interactive analysis based on the data from Genotype-Tissue Expression (GTEx) and TCGA database ${ }^{[33]}$, was utilized in this study to analyze the association between MMP1 expression and patient prognostic potential in a variety of cancers. As a complement to the analysis by the Kaplan-Meier Plotter database, we charted survival curves for overall survival (OS) and disease-free survival (DFS) via GEPIA using the log-rank and Mantel-Cox tests. The Spearman's rank correlation coefficient was calculated with default parameters.

\section{TIMER Database Analysis}

The TIMER 2.0 database (http://timer.comp-genomics.org), incorporating 10,009 samples across 23 cancer types from TCGA, is a comprehensive web resource for the systematical evaluation of the clinical relevance of tumor-immune infiltrates and differential gene correlation analysis ${ }^{[34]}$. We selected MMP1 under the gene expression module with the default parameters to obtain heatmaps visualizing the correlation of its expression with different immune infiltrate levels in different cancer types by the purity-adjusted spearman's test. Of the various TIICs, B cells, CD $4+T$ cells, CD8 + T cells, macrophages, neutrophils and dendritic cells ${ }^{[35,36]}$ were selected for investigation in this study to assess the relationship between MMP1 and tumor-immunity in HCC based on insight from previous studies. Furthermore, correlation analysis was conducted to investigate the relationship between MMP1 expression and different biomarker genes of TIICs as reported in other papers ${ }^{[37,38]}$, including B cells, CD8 + T cells, Monocytes, tumor-associated macrophages (TAMs), M1 and M2 macrophages, neutrophils, dendritic cells, Tregs and exhausted T cells. Result delineation was attained through Spearman's rho and p-value adjusted by purity.

\section{Sangerbox database analysis}

Sangerbox database (http://www.sangerbox.com) is a tool to facilitate a variety of biological information analysis, visualization mapping and convenient data download functions, based on TCGA and GEO databases ${ }^{[39]}$. We investigated the correlation between MMP1 expression levels and the tumor mutational burden (TMB) and microsatellite instability (MSI) in pan-carcinomas using pearson's method.

\section{Statistical analysis}

All statistical analysis and graphing was performed with R (version 4.0.3) and STATA software (College Station, TX: Stata Corp LP, USA). Survival curves were created by the GEPIA and Kaplan-Meier plots database based on R. Forest plots were generated by meta-analysis in metan module of STATA. The relationship between MMP1 expression and TMB and MSI in pan-cancers was evaluated by Pearson's correlation, while the sperman's correlation was used to assess the relationship between MMP1 expression and TIICs, as well as biomarkers. A $p$ value $<0.05$ was considered statistically significant. The correlations were defined as follows: 0.00-0.19 (none), 0.20-0.39 (low), 0.40-0.59 (moderate), 0.60-.079 (high), $\geq 0.80$ (very high) $^{[40]}$.

\section{Results}

\section{MMP1 expression in HCC and other carcinomas}

MMP1 expression inhibition would ultimately contribute to prevention of HCC progression, according to a previous study ${ }^{[41]}$. In order to confirm the carcinogenesis of MMP1 in HCC, we utilized the Oncomine database to evaluate the levels of MMP1 expression in both tumor and normal tissues of various cancers. Except kidney cancer as well as brain and central nervous system cancer which have a reduced expression of MMP1, together with leukemia, liver cancer and myeloma with censored data, the expression levels of MMP1 gene were upregulated significantly in other types of tumor tissues compared to their respective adjacent normal tissues; including bladder, breast, cervical, colorectal, esophageal, gastric, head and neck, lung, lymphoma, melanoma, ovarian, pancreatic, prostate, and sarcoma cancer tissues (Fig. 1A). Although no discernible relationship between MMP1 expression and HCC was observed using Oncomine, further assessment of MMP1 RNA-seq expression in HCC using TIMER 2.0 based on the TCGA database, indicated that a high expression of MMP1 in 22 types of cancers was detected, including HCC, $p$-value $<0.001$ (Fig. 1B). These results strongly suggested that the overexpression of MMP1 might play a positive role in the progression of different neoplasms, especially in HCC.

\section{Evaluation of MMP1 expression and HCC prognosis}

The Kaplan-Meier plotter and GEPIA database were used to evaluate the prognostic potential of MMP1 transcriptional levels in HCC tissues. Interestingly, we found that higher expression of MMP1 was associated with poorer prognosis in patients with HCC (Fig. 2A, disease-specific survival (DSS): HR = 2.41, $95 \%$ CI $=1.55-3.76, p=6.1 \mathrm{e}-05, \mathrm{n}=357$; Fig. 2B, overall survival (OS): $\mathrm{HR}=2.1,95 \% \mathrm{Cl}=1.49-2.98, p=1.7 \mathrm{e}-05, \mathrm{n}=364$; Fig. $2 \mathrm{C}$, progression free survival (PFS): HR= $1.96,95 \% \mathrm{Cl}=1.46-2.63, p=5.9 \mathrm{e}-06, \mathrm{n}=366$; Fig. 2D, relapse free survival (RFS): $\mathrm{HR}=1.79,95 \% \mathrm{Cl}=1.27-2.5, p=0.00065, \mathrm{n}=313$ ). Additionally, we got consistent results with statistical significance in the GEPIA database (Fig. 2E, disease free survival (DFS): HR=1.4, $p=0.018 ; \mathrm{Fig} .2 \mathrm{~F}, \mathrm{OS}$ : HR=2, $p=0.00023$ ).

Next, we investigated the relationship between the levels of MMP1 expression and the related prognostic in other cancers through the Kaplan-Meier plotter analysis. Similarly, the survival curves showed that high expression of MMP1 in tumor tissues was relevant to poor prognosis in different cancers. For example, poor OS, RFS, post progression survival (PPS) and distant metastasis-free survival (DMFS) in breast cancer were observed to be highly correlated with strong expression of MMP1 (Fig. 3A, OS: $\mathrm{HR}=1.54,95 \% \mathrm{Cl}=1.27-1.86, p=7.6 \mathrm{e}-06$; $\mathrm{PPS}$ : $\mathrm{HR}=1.37,95 \% \mathrm{Cl}=1.08-1.73, p=0.0084 ; \mathrm{RFS}$ : $\mathrm{HR}=1.7,95 \% \mathrm{Cl}$ $=1.54-1.88, p<1 \mathrm{e}-16$; DMFS: $\mathrm{HR}=1.67,95 \% \mathrm{Cl}=1.43-1.95, p=1.1 \mathrm{e}-10)$. On the other hand, only poor OS in gastric cancer $(\mathrm{Fig} .3 \mathrm{~B}, \mathrm{HR}=0.75,95 \% \mathrm{Cl}=0.63-$ 
$0.9, p=0.0021$ ), ovarian cancer (Fig. $3 \mathrm{C}, \mathrm{HR}=1.15,95 \% \mathrm{Cl}=1.01-1.31, p=0.04$ ) and lung cancer (Fig. 3D, $\mathrm{HR}=1.16,95 \% \mathrm{Cl}=1-1.35, p=0.047$ ) respectively, was related to high expression of MMP1.

As a supplement, we assessed the relationship between MMP1 transcriptional level and the other tumor tissues via GEPIA database. The high expression of MMP1 was associated with poor OS in head and neck squamous cell carcinoma (HNSC), cervical squamous cell carcinoma and endocervical adenocarcinoma (CESC), pancreatic adenocarcinoma (PAAD) (Fig. 4B, E, F), poor DFS in glioblastoma multiforme (GBM) (Fig. 4A), and both in kidney chromophobe (KICH) and kidney renal papillary cell carcinoma (KIRP) (Fig. 4C, D).

\section{Correlation analysis between MMP1 expression and clinical characteristics of patients with HCC}

Furthermore, we evaluated the correlation between MMP1 expression levels and clinicopathological factors in HCC using STATA based on the data of KaplanMeier plotter database (Table.1). The characteristics were classified into several subgroups based on stage, grade, ACJJ-T, gender, vascular invasion, race, alcohol consumption, and hepatitis virus. Almost all were independent risk factors for the prognosis of HCC patients with high expression of MMP1 (Fig. 5AD). In particular, the higher expression of MMP1 was closely associated with worse OS, PFS, RFS and DSS rates in relation to the following factors: grades II (OS: $\mathrm{HR}=1.98,95 \% \mathrm{Cl}=1.18-3.33, p=0.0082$; PFS: $\mathrm{HR}=2.57,95 \% \mathrm{Cl}=1.66-3.98, p=1.2 \mathrm{e}-05 ; \mathrm{RFS}: \mathrm{HR}=2.39,95 \% \mathrm{Cl}=1.4-4.06, p=9.3 \mathrm{e}-04 ; \mathrm{DSS}: \mathrm{HR}=3.14$, $95 \% \mathrm{Cl}=1.54-6.39, p=8.9 \mathrm{e}-04)$, male (OS: $\mathrm{HR}=2.9,95 \% \mathrm{Cl}=1.86-4.52, p=8.3 \mathrm{e}-07 ; \mathrm{PFS}: \mathrm{HR}=1.86,95 \% \mathrm{Cl}=1.29-2.67, p=6.8 \mathrm{e}-04 ; \mathrm{RFS}: \mathrm{HR}=1.75,95 \% \mathrm{Cl}=$ 1.17-2.61, $p=0.0057$; DSS: $\mathrm{HR}=3.4,95 \% \mathrm{Cl}=1.92-6.02, p=7.9 \mathrm{e}-06)$, Asian (OS: $\mathrm{HR}=3.88,95 \% \mathrm{Cl}=2.14-7.06, p=1.7 \mathrm{e}-06$; PFS: $\mathrm{HR}=2.28,95 \% \mathrm{Cl}=1.41-$ $3.68, p=5.4 \mathrm{e}-04$; RFS: $\mathrm{HR}=2.11,95 \% \mathrm{Cl}=1.26-3.52, p=0.0038$; DSS: $\mathrm{HR}=4.27,95 \% \mathrm{Cl}=1.93-9.46, p=1 \mathrm{e}-04)$, non-vascular invasion (OS: $\mathrm{HR}=2.09,95 \% \mathrm{Cl}$ $=1.24-3.55, p=0.005 ; \mathrm{PFS}: \mathrm{HR}=1.77,95 \% \mathrm{Cl}=1.13-2.77, p=0.011 ; \mathrm{RFS}: \mathrm{HR}=1.84,95 \% \mathrm{Cl}=1.08-3.15, p=0.023 ; \mathrm{DSS}: \mathrm{HR}=2.16,95 \% \mathrm{Cl}=1.04-4.5, p=$ 0.035), non-alcoholics (OS: $\mathrm{HR}=2.59,95 \% \mathrm{Cl}=1.47-4.58, p=6.7 \mathrm{e}-04 ; \mathrm{PFS}: \mathrm{HR}=1.93,95 \% \mathrm{Cl}=1.28-2.9, p=0.0013 ; \mathrm{RFS}: \mathrm{HR}=1.91,95 \% \mathrm{Cl}=1.14-3.21, p=$ 0.013; DSS: $\mathrm{HR}=4.1,95 \% \mathrm{Cl}=1.72-9.78, p=5.8 \mathrm{e}-04)$, patients with hepatitis virus infection (OS: $\mathrm{HR}=3.33,95 \% \mathrm{Cl}=1.73-6.39, p=1.3 \mathrm{e}-04 ; \mathrm{PFS}$ : $\mathrm{HR}=2.02$, $95 \% \mathrm{Cl}=1.27-3.22, p=0.0026$; RFS: $\mathrm{HR}=1.75,95 \% \mathrm{Cl}=1.06-2.87, p=0.026$; DSS: $\mathrm{HR}=3.54,95 \% \mathrm{Cl}=1.55-8.08, p=0.0014)$ and those without it $(\mathrm{OS}: \mathrm{HR}=$ $1.76,95 \% \mathrm{Cl}=1.1-2.8, p=0.017 ; \mathrm{PFS}: \mathrm{HR}=2.19,95 \% \mathrm{Cl}=1.41-3.39, p=3.3 \mathrm{e}-04 ; \mathrm{RFS}: \mathrm{HR}=1.99,95 \% \mathrm{Cl}=1.2-3.31, p=0.0066 ; \mathrm{DSS}: \mathrm{HR}=2.41,95 \% \mathrm{Cl}=$ $1.31-4.44, p=0.0037)$. These findings indicated that high expression of MMP1 might be one of the contributing factors to poor prognosis in HCC patients with different clinical characteristics.

\section{MMP1 expression levels and TIICs in HCC}

Tumor infiltrating immunocytes have been shown to influence the progression of patients with different cancers. Thus, it's necessary for us to investigate any relationship between MMP1 expression and TIICs in HCC via TIMER database. Consistent with previous survival results, a high expression level of MMP1 was positively related with a number of TIICs and notable outcomes (Fig. 6). It was associated with high infiltration levels of $B$ cells (Rho $=0.268, p=4.31 \mathrm{e}-07$ ), dendritic cells (Rho $=0.432, p=4.01 \mathrm{e}-17)$, macrophages (Rho $=0.263, p=7.39 \mathrm{e}-07)$, neutrophils (Rho $=0.268, p=4.52 \mathrm{e}-07), \mathrm{CD} 4+\mathrm{T}$ cells $(\mathrm{Rho}=0.116, p=$ 3.07e-02), and CD8 + T cells (Rho $=0.108, p=4.57 \mathrm{e}-02)$ (Fig. 6). On the contrary, MMP1 expression was not correlated with tumor purity $(\mathrm{Rho}=0.056, p=3.00 \mathrm{e}-$ 01), indicating that perhaps it originates from the cells in the tumor-immunity microenvironment.

\section{Gene analysis for MMP1 and Immune cell subset biomarkers}

Besides verifying the positive correlation between MMP1 expression and several TIICs, we proceeded to test the correlation of MMP1 expression with levels of specific biomarker genes in the select TIICs or their subsets in HCC tissues vias TIMER database and explore MMP1-involved carcinogenic mechanisms and filtrate promising therapeutic targets in the future. In detail, the correlation analysis was conducted with with/without adjustment by purity, indicating significantly positive correlation of co-expression of MMP1 and biomarker genes of TIICs or subsets of them (Fig. 7). What we found was that almost all the biomarker genes we investigated were positively related to MMP1 expression, including CD19 (B cell biomarker, $\mathrm{R}=0.147, p=6.35 \mathrm{e}-03$ ), $\mathrm{CD} 79 \mathrm{~A}$ ( $\mathrm{B}$ cell biomarker, $\mathrm{R}=0.155, p=3.8 \mathrm{e}-03)$ (Fig. 7A), CD8A (CD8 + T cell biomarker, $\mathrm{R}=0.209, p=9.55 \mathrm{e}-05), \mathrm{CD} 8 \mathrm{~B}(\mathrm{CD} 8+\mathrm{T}$ cell biomarker, $\mathrm{R}=0.239, p=7.09 \mathrm{e}-06)$ (Fig. 7B), CD86 (Monocyte biomarker, $\mathrm{R}=0.377, p=4.03 \mathrm{e}-13$ ), CSF1R (Monocyte biomarker, $\mathrm{R}=0.29, p=4.06 \mathrm{e}-08$ ) (Fig. 7C), IRF5 (M1 Macrophage biomarker, $\mathrm{R}=0.168, p=1.69 \mathrm{e}-03)$, PTGS2 (M1 Macrophage biomarker, $\mathrm{R}=0.201, p=1.65 \mathrm{e}-04)$ (Fig. 7D), CD163 (M2 Macrophage biomarker, $\mathrm{R}=0.158, p=3.18 \mathrm{e}-03)$, VSIG4 (M2 Macrophage biomarker, $\mathrm{R}=0.173, p=1.25 \mathrm{e}-03$ ), MS4A4A (M2 Macrophage biomarker, $\mathrm{R}=0.196, p=2.51 \mathrm{e}-04)$ (Fig. 7E), ITGAM (Neutrophils biomarker, $\mathrm{R}=0.364, p=2.84 \mathrm{e}-12$ ) (Fig. 7F), CCL2 (tumor-associated macrophage (TAM) biomarker, $\mathrm{R}=0.189, p=4.15 \mathrm{e}-04)$, CD68 (TAM biomarker, $\mathrm{R}=0.325$, $p=6.6 \mathrm{e}-10)$, IL10 (TAM biomarker, $\mathrm{R}=0.326, p=5.7 \mathrm{e}-10$ ) (Fig. 7H), HLA-DPB1 (Dendritic cell biomarker, $\mathrm{R}=0.227, p=2.11 \mathrm{e}-05)$, HLA-DQB1 (Dendritic cell biomarker, $\mathrm{R}=0.237, p=8.36 \mathrm{e}-06$ ), HLA-DRA (Dendritic cell biomarker, $\mathrm{R}=0.251, p=2.37 \mathrm{e}-06$ ), HLA-DPA1 (Dendritic cell biomarker, $\mathrm{R}=0.219, p=4.02 \mathrm{e}-05$ ), CD1c (Dendritic cell biomarker, $\mathrm{R}=0.12, p=2.57 \mathrm{e}-02$ ), NRP1 (Dendritic cell biomarker, $\mathrm{R}=0.218, p=4.29 \mathrm{e}-05$ ), and ITGAX (Dendritic cell biomarker, $\mathrm{R}=0.419, p$ $=4.38 \mathrm{e}-16$ ) (Fig. 7l), as well as the biomarker genes of subsets of T cells, such as FOXP3 (Tregs biomarker, $\mathrm{R}=0.172, p=1.33 \mathrm{e}-03$ ), CCR8 (Tregs biomarker, $\mathrm{R}$ $=0.311, p=3.53 \mathrm{e}-09$ ), TGFB1 (Tregs biomarker, $\mathrm{R}=0.277, p=1.67 \mathrm{e}-07$ ), IL2RA (Tregs biomarker, $\mathrm{R}=0.356, p=1.02 \mathrm{e}-11$ ), CD4 (Tregs biomarker, $\mathrm{R}=0.247, p=$ 3.34e-06) (Fig. 7G), PDCD-1 (T cell exhaustion biomarker, $\mathrm{R}=0.268, p=4.55 \mathrm{e}-07$ ), CTLA4 (T cell exhaustion biomarker, $\mathrm{R}=0.386, p=1.02 \mathrm{e}-13$ ), LAG3 (T cell exhaustion biomarker, $\mathrm{R}=0.2, p=1.86 \mathrm{e}-04$ ), HAVCR2 (T cell exhaustion biomarker, $\mathrm{R}=0.436, p=1.8 \mathrm{e}-17$ ), $\mathrm{BTLA}$ ( $\mathrm{T}$ cell exhaustion biomarker, $\mathrm{R}=0.121, p=$ 2.49e-02), TIGIT (T cell exhaustion biomarker, $\mathrm{R}=0.348, p=3.14 \mathrm{e}-11$ ), and GZMB (T cell exhaustion biomarker, $\mathrm{R}=0.206, p=1.12 \mathrm{e}-04)(\mathrm{Fig} .7 \mathrm{~J})$.

\section{Expression levels of MMP1 related to TMB and MSI in HCC}

Studies have increasingly reported that $\mathrm{TMB}^{[42]}$ and $\mathrm{MSI}^{[43]}$ could be used as predictive biomarkers for cancer immunotherapy, which might be the one of most popular methods to predict the therapeutic efficiency of immunotherapy on carcinomas. Therefore, we investigated the correlation between MMP1 expression and TMB/MSI in 32 types cancers via SangerBox. Contrary to what would be expected, there was no significant correlation between MMP1 expression and 
TMB/MSI in HCC patients. It was only positively related to TMB in lung adenocarcinoma (LUAD) $(p=0.0024)$, prostate adenocarcinoma (PRAD) ( $p=0.046)$, sarcoma (SARC) $(p=0.013)$, breast invasive carcinoma (BRCA) $(p=7.3 \mathrm{e}-05)$, colon adenocarcinoma (COAD) ( $p=0.0017)(\mathrm{Fig}$. 8A) and MSI in testicular germ cell tumors (TGCT) ( $p=0.00095)$, kidney renal clear cell carcinoma (KIRC) ( $p=6 \mathrm{e}-04)$, and COAD ( $p=3.2 \mathrm{~d}-07)$ (Fig. 8B). In addition, negative correlation was only observed between MMP1 expression and TMB in head and neck squamous cell carcinoma (HNSC) ( $p=-0.0079)$ (Fig. 8A) and MSI in pancreatic adenocarcinoma (PAAD) ( $p=-0.023)$. This might indicate that HCC patients with neither high nor low expression of MMP1 could equally benefit from TMB/MSI targeted immunotherapy.

\section{Discussion}

Although the incidence and mortality of HCC have decreased in South-Eastern Asia due to hepatitis vaccination progress, it is still one of the leading causes of cancer related deaths world wide ${ }^{[1]}$. Lack of efficient prognostic factors leads to delayed diagnosis and intervention, which in turn considerably contribute to poor HCC patient survival. In this study, we demonstrated that MMP1 expression was elevated in HCC and was significantly correlated with worse prognosis utilizing a bioinformatic analysis method based on public databases resources. The MMP1 expression had a positive relationship with differential TIICs and various immune-related gene biomarkers in HCC. All the findings suggested an underlying mechanism of MMP1 expression in remodulating the tumorimmunity microenvironment and immune escape. To our knowledge, our study is the first one to comprehensively reveal the prognostic value of MMP1 and its relationship with immune infiltration in HCC. MMP1, as a member of MMPs, participated in the EMT which was identified as a strict programmed shift playing a crucial role in tumor invasion and metastasis ${ }^{[4]}$. MMPs could auto-activate and lead to a cascade of interactional activation between each other to enhance their influence in the EMT ${ }^{[19]}$. For invasive $\mathrm{HCC}$, overexpression of MMP1 has been confirmed to correlate with an elevated capacity of invasion and migratory in HCC cells, by the most likely mechanism of ECM degradation promoting the transmembrane migration of tumor cells ${ }^{[17]}$. This speculation explained the outcomes of high expression of MMP1 in tumor tissues and poor prognosis in HCC patients to a certain extent. On the other hand, MMP1-mediated HCC progression could be suppressed by circularDLC1 ${ }^{[41]}$, miR-526b ${ }^{[45]}$, ETV4-MMP1 axis ${ }^{[46]}$ and ERK/MMP1 signaling pathway ${ }^{[47]}$, indicating multiple pathological pathways of MMP1 carcinogenesis on HCC.

Two databases were utilized for mutual confirmation of the positive relationship between HCC prognosis and MMP1 expression, including OS, PFS, DSS, RFS, and DFS. High expression of MMP1 is closely related to poor survival in various of tumors, which is consistent with our finding thus highlighting the significance of monitoring MMP1 expression level to in attempts to detect and prevent early recurrence. However, MMP1 expression was not highly correlated with all clinicopathological characteristics, subgroups indicating some unknown factors might influence the prognosis in conjunction with these subgroups.

According to resent studies, the integration of clinicopathologic characteristics and TIICs can be a clinical predictive model for the efficiency of immunotherapy ${ }^{[48,49]}$. The genesis and development of tumors can involve large numbers of immune infiltrating cells and inflammatory mediators. Although MMP1 is involved in the tumor-immune-related progression of some carcinomas, there is barely any studies regarding the interaction between MMP1 expression and TIICs in HCC proliferation and migration. Our study, presents a positive interaction between MMP1 expression and TIICs, signifying the probable utility of MMP1-based prediction in HCC patients associated with immune infiltration. However, the absence of an apparent correlation between MMP1 and tumor purity indicated that MMP1 was expressed from cells in the tumor microenvironment, most likely from TIICs. Although the function of TIICs in carcinogenesis is still controversial, a cluster of studies have reported that MMP1 alongside TIICs plays a vital role in tumor progression ${ }^{[50-52]}$. For further investigation of the interrelationship between MMP1 expression and immune cells infiltration in HCC, we analyzed the data via cox regression. B cells,

CD8+/CD4 + T cells and dendritic cells are specific immune cells playing major roles in activating the body's immune response with antitumor effects ${ }^{[53,54]}$. On the contrary, reports on TAMs have been focused on their function of modulating the tumor microenvironment and promoting tumor proliferation and angiogenesis ${ }^{[55]}$. In our study, all of the immune cells showed a high degree of infiltration in HCC, with almost opposite pro- and anti-tumor activity. The results suggest that high expression of MMP1 may overall promote HCC carcinogenesis via increasing infiltration of TAMs, partially counteracting the antitumor activity of other immune cells. This discovery might contribute to the development of innovative immunotherapeutic agents for HCC patients who do not respond to the current immunosuppressive checkpoint inhibitors. Moreover, the results of TMB/MSI evaluation suggested the patients with HCC might not readily benefit from the treatment of PD-1, necessitating the exploration of inhibitors targeted to new immunosuppressive site.

Coupled with the rapid development of immunotherapy in the origination and progression of cancer, the function and mechanism of tumor-immunity microenvironment have been the frontier area for research to screen out related genes that can serve as innovative biomarkers for diagnosis and prognosis or therapeutic targets ${ }^{[56]}$. We interestingly found that almost all the expression levels of related gene biomarkers in TIICs were positively correlated with MMP1 expression, as well positive correlation between TIICs and MMP1 expression. Furthermore, in spite of the anti-tumor activity of gene biomarkers in B cells, CD8 + T cells, dendritic cells and M1 Macrophages, large numbers of biomarkers in Tregs and exhausted T cells which exerted pro-tumor activity of immuneescaping and angiogenesis were observed. This consequence can explain how the MMP1 expression influence the TIICs and related gene biomarkers to promote the progression of $\mathrm{HCC}$ to a certain extent, indicating the complex mechanisms of interaction and tumorigenesis in tumor microenvironment.

There were several notable limitations to our study. First, the data in our study being collected and analyzed based on the big data from authoritative databases as comprehensively as possible, it can only provide a primary theoretical basis and needs further verification by animal experiments and clinical trials. Second, different statistics methods used in data analysis might lead to differentials in results. Furthermore, the correlation coefficients between MMP1 and TIICs or their biomarker genes were not very strong, suggesting the important direction and terra incognita for further research.

In conclusion, our study revealed that the high expression of MMP1 was closely related with poor prognosis in HCC patients, so is the positive correlation with tumor-immune cell infiltration. Although some mechanisms of interactive network are unknown, we still have reason to believe that MMP1 is a prospective prognostic biomarker in HCC. 


\section{Declarations}

\section{Ethical approval}

All procedures performed in studies involving human participants were in accordance with the ethical standards of the research ethics committee of Lihuili hospital affiliated to Ningbo University at which the studies were conducted (Approval no. KY2021PJ045) and with the 1964 Helsinki declaration and its later amendments or comparable ethical standards. Informed consent Since this was an observational but not prospective intervention study, the Ethics Committee provided a waiver of informed consent.

\section{Conflict of interest}

The authors have declared that no conflict of interest exists.

Acknowledgements

Not applicable.

Funding

This study was supported by Ningbo Health Branding Subject Fund (PPXK2018-03)

Authors' contributions

Conception and writing, L.D; Charting and writing, J.M; data analysis, X.C.C and S.Q.M; reference acquisition, T.Y.Z and H.H.S; comments and suggestions, C.D.L; manuscript revision, C.J.L. All the authors approved the final manuscript to be submitted and published.

\section{Consent to publish}

All the authors approved the final manuscript to be submitted and published.

\section{Availability of Data and Materials}

All the data and materials can be obtained in open bioinformation databases mentioned above in our manuscript.

\section{References}

1. Sung H, Ferlay J, Siegel RL, Laversanne M, Soerjomataram I, Jemal A, Bray F. Global cancer statistics 2020: GLOBOCAN estimates of incidence and mortality worldwide for 36 cancers in 185 countries. CA Cancer J Clin. 2021 Feb 4. doi:10.3322/caac.21660.

2. Makarova-Rusher OV, Altekruse SF, McNeel TS, Ulahannan S, Duffy AG, Graubard BI, Greten TF, McGlynn KA. Population attributable fractions of risk factors for hepatocellular carcinoma in the United States. Cancer. 2016 Jun 1;122(11):1757-65. doi: 10.1002/cncr.29971.

3. Xie DY, Ren ZG, Zhou J, et al. 2019 Chinese clinical guidelines for the management of hepatocellular carcinoma: updates and insights. Hepatobiliary Surg Nutr. 2020 Aug;9(4):452-63.

4. Kudo M, Finn RS, Qin S, et al. Lenvatinib versus sorafenib in first-line treatment of patients with unresectable hepatocellular carcinoma: a randomised phase 3 non-inferiority trial. Lancet. 2018 Mar;24(10126):1163-73. 391(.

5. Bruix J, Qin S, Merle P, et al. Regorafenib for patients with hepatocellular carcinoma who progressed on sorafenib treatment (RESORCE): a randomised, double-blind, placebo-controlled, phase 3 trial. Lancet. 2017 Jan 7;389(10064):56-66.

6. Zhu AX, Finn RS, Edeline J, et al. Pembrolizumab in patients with advanced hepatocellular carcinoma previously treated with sorafenib (KEYNOTE-224): a non-randomised, open-label phase 2 trial. Lancet Oncol. 2018 Jul;19(7):940-52.

7. Zhou J, Sun HC, Wang Z, Cong WM, Wang JH, Zeng MS, et al. Guidelines for Diagnosis and Treatment of Primary Liver Cancer in China (2017 Edition). Liver Cancer. 2018 Sep;7(3):235-60. doi:10.1159/000488035.

8. Zeng H, Chen W, Zheng R, et al. Changing cancer survival in China during 2003-15: a pooled analysis of 17 population-based cancer registries. Lancet Glob Health. 2018 May;6(5): e555-e567.

9. Siegel RL, Miller KD, Jemal A. Cancer statistics. 2018. CA Cancer J Clin. 2018 Jan;68(1):7-30.

10. Australian Institute of Health and Welfare. Cancer in Australia: Actual incidence data from 1982 to 2013 and mortality data from 1982 to 2014 with projections to 2017. Asia Pac J Clin Oncol. 2018 Feb;14(1):5-15.

11. Brkic M, Balusu S, Libert C, Vandenbroucke RE, "Friends or foes: matrix metalloproteinases and their multifaceted roles in neurodegenerative diseases," Mediators of Inflammation, vol. 2015, Article ID 620581, 27 pages, 2015.

12. García-Irigoyen $\mathrm{O}$, Latasa MU, Carotti S, et al. Matrix metalloproteinase 10 contributes to hepatocarcinogenesis in a novel crosstalk with the stromal derived factor 1/C-X-C chemokine receptor 4 axis. Hepatology. 2015;62(1):166-78.

13. Gao PT, Ding GY, Yang X, et al. Invasive potential of hepatocellular carcinoma is enhanced by loss of selenium-binding protein 1 and subsequent upregulation of CXCR4. American Journal of Cancer Research. 2018;8(6):1040-9.

14. Wang B, Ding Y-M, Fan P, Wang B, Xu J-H, Wang W-X. Expression and significance of MMP2 and HIF-1a in hepatocellular carcinoma. Oncology Letters. 2014;8(2):539-46. 
15. Nwosu ZC, Megger DA, Hammad S, et al., "Identification of the consistently altered metabolic targets in human hepatocellular carcinoma," Cellular and Molecular Gastroenterology and Hepatology, vol. 4, no. 2, pp. 303-323.e1, 2017.

16. Duarte S, Baber J, Fujii T, Coito AJ. "Matrix metalloproteinases in liver injury, repair and fibrosis," Matrix Biology, vol. 44-46, pp. 147-156, 2015.

17. Lai Y-L, Gong C-L, Fu C-K, et al. The contribution of matrix metalloproteinase-1 genotypes to hepatocellular carcinoma susceptibility in Taiwan. Cancer Genomics Proteomics. 2017;14(2):119-25.

18. Zhu XM, Sun WF. Association between matrix metalloproteinases polymorphisms and ovarian cancer risk: A meta-analysis and systematic review. PLoS One. 2017;12(9):e0185456. doi:10.1371/journal.pone.0185456. Published 2017 Sep 28.

19. Scheau C, Badarau IA, Costache R, Caruntu C, Mihai GL, Didilescu AC, Constantin C, Neagu M. The Role of Matrix Metalloproteinases in the EpithelialMesenchymal Transition of Hepatocellular Carcinoma. Anal Cell Pathol (Amst). 2019 Nov 26;2019:9423907. doi: 10.1155/2019/9423907. PMID: 31886121; PMCID: PMC6899323.

20. Zhou H, Xiang Q, Hu C, Zhang J, Zhang Q, Zhang R. Identification of MMP1 as a potential gene conferring erlotinib resistance in non-small cell lung cancer based on bioinformatics analyses. Hereditas. 2020 Jul 23;157(1):32. doi: 10.1186/s41065-020-00145-x.

21. Yang MD, Lin KC, Lu MC, Jeng LB, Hsiao CL, Yueh TC, et al. Contribution of matrix metalloproteinases-1 genotypes to gastric cancer susceptibility in Taiwan. Biomedicine (Taipei). 2017 Jun;7(2):10. doi:10.1051/bmdcn/2017070203.

22. Liu X, Zhou ZH, Li W, Zhang SK, Li J, Zhou MJ, Song JW. Heparanase Promotes Tumor Growth and Liver Metastasis of Colorectal Cancer Cells by Activating the p38/MMP1 Axis. Front Oncol. 2019 Apr;2:9:216. doi:10.3389/fonc.2019.00216.

23. Zhou H, Zhu X. Association between matrix-metalloproteinase polymorphisms and prostate cancer risk: a meta-analysis and systematic review. Cancer Manag Res. 2018 Nov 2;10:5247-5259. doi: 10.2147/CMAR.S177551.

24. Liu LZ, Zhang Z, Zheng BH, Shi Y, Duan M, Ma LJ, et al. CCL15 Recruits Suppressive Monocytes to Facilitate Immune Escape and Disease Progression in Hepatocellular Carcinoma. Hepatology. 2019 Jan;69(1):143-59. doi:10.1002/hep.30134.

25. Cabrita R, Lauss M, Sanna A, Donia M, Skaarup Larsen M, Mitra S, et al. Tertiary lymphoid structures improve immunotherapy and survival in melanoma. Nature. 2020 Jan;577(7791):561-565. doi: 10.1038/s41586-019-1914-8.

26. Fu Y, Liu S, Zeng S, Shen H. From bench to bed: the tumor immune microenvironment and current immunotherapeutic strategies for hepatocellular carcinoma. J Exp Clin Cancer Res. 2019 Sep 9;38(1):396. doi: 10.1186/s13046-019-1396-4.

27. Ou Z, Wang Y, Liu L, Li L, Yeh S, Qi L, Chang C. Tumor microenvironment B cells increase bladder cancer metastasis via modulation of the IL-8/androgen receptor (AR)/MMPs signals. Oncotarget. 2015 Sep 22;6(28):26065-78. doi: 10.18632/oncotarget.4569.

28. Morishita A, Gerber A, Gow CH, Zelonina T, Chada K, D'Armiento J. Cell Specific Matrix Metalloproteinase-1 Regulates Lung Metastasis Synergistically with Smoke Exposure. J Cancer Res Forecast. 2018;1(2):1014.

29. Wu MH, Tsai YT, Hua KT, Chang KC, Kuo ML, Lin MT. Eicosapentaenoic acid and docosahexaenoic acid inhibit macrophage-induced gastric cancer cell migration by attenuating the expression of matrix metalloproteinase 10. J Nutr Biochem. 2012 Nov;23(11):1434-9. doi:10.1016/j.jnutbio.2011.09.004.

30. Petrella BL, Vincenti MP. Interleukin-1 $\beta$ mediates metalloproteinase-dependent renal cell carcinoma tumor cell invasion through the activation of CCAAT enhancer binding protein $\beta$. Cancer Med. 2012 Aug;1(1):17-27. doi:10.1002/cam4.7.

31. Rhodes DR, Kalyana-Sundaram S, Mahavisno V, Varambally R, Yu J, Briggs BB, et al. Oncomine 3.0: genes, pathways, and networks in a collection of 18,000 cancer gene expression profiles. Neoplasia. 2007 Feb;9(2):166-80. doi: 10.1593/neo.07112. PMID: 17356713; PMCID: PMC1813932.

32. Nagy Á, Lánczky A, Menyhárt O, Győrffy B. Validation of miRNA prognostic power in hepatocellular carcinoma using expression data of independent datasets. Sci Rep. 2018 Jun 15;8(1):9227. doi: 10.1038/s41598-018-27521-y. Erratum in: Sci Rep. 2018 Jul 26;8(1):11515.

33. Tang Z, Li C, Kang B, Gao G, Li C, Zhang Z. GEPIA: a web server for cancer and normal gene expression profiling and interactive analyses. Nucleic Acids Res. 2017 Jul 3;45(W1): W98-W102. doi: 10.1093/nar/gkx247.

34. Li B, Severson E, Pignon JC, Zhao H, Li T, Novak J, et al. Comprehensive analyses of tumor immunity: implications for cancer immunotherapy. Genome Biol. 2016 Aug 22;17(1):174. doi: 10.1186/s13059-016-1028-7.

35. Xie XW, Jiang SS, Li X. CLEC3B as a Potential Prognostic Biomarker in Hepatocellular Carcinoma. Front Mol Biosci. 2021 Jan 20;7:614034. doi: $10.3389 /$ fmolb.2020.614034.

36. Danaher P, Warren S, Dennis L, D'Amico L, White A, Disis ML, et al. Gene expression markers of Tumor Infiltrating Leukocytes. J Immunother Cancer. 2017 Feb 21;5:18. doi: 10.1186/s40425-017-0215-8.

37. Wu X, Qu D, Weygant N, Peng J, Houchen CW. Cancer Stem Cell Marker DCLK1 Correlates with Tumorigenic Immune Infiltrates in the Colon and Gastric Adenocarcinoma Microenvironments. Cancers (Basel). 2020 Jan 22;12(2):274. doi: 10.3390/cancers12020274.

38. Song D, Wang Y, Zhu K, Tian L, Gao Q, Zhou J, Fan J, Wang X. DCK is a promising prognostic biomarker and correlated with immune infiltrates in hepatocellular carcinoma. World J Surg Oncol. 2020 Jul 20;18(1):176. doi: 10.1186/s12957-020-01953-1.

39. Zhang S, Yu S, Wang J, Cheng Z. Identification of PSMD7 as a prognostic factor correlated with immune infiltration in head and neck squamous cell carcinoma. Biosci Rep. 2021 Mar 26;41(3):BSR20203829. doi: 10.1042/BSR20203829.

40. Barnett LM, Lai SK, Veldman SLC, Hardy LL, Cliff DP, Morgan PJ, et al. Correlates of Gross Motor Competence in Children and Adolescents: A Systematic Review and Meta-Analysis. Sports Med. 2016 Nov;46(11):1663-88. doi:10.1007/s40279-016-0495-z.

41. Liu H, Lan T, Li H, Xu L, Chen X, Liao H, et al. Circular RNA circDLC1 inhibits MMP1-mediated liver cancer progression via interaction with HuR. Theranostics. 2021 Jan 1;11(3):1396-1411. doi: 10.7150/thno.53227.

42. Chang L, Chang M, Chang HM, Chang F. Microsatellite Instability: A Predictive Biomarker for Cancer Immunotherapy. Appl Immunohistochem Mol Morphol. 2018 Feb;26(2):e15-21. doi:10.1097/PAl.0000000000000575.

Page 7/17 
43. Chang L, Chang M, Chang HM, Chang F. Microsatellite Instability: A Predictive Biomarker for Cancer Immunotherapy. Appl Immunohistochem Mol Morphol. 2018 Feb;26(2):e15-21. doi:10.1097/PAl.0000000000000575.

44. Lin H, Yang B, Teng M. T-cell immunoglobulin mucin-3 as a potential inducer of the epithelial-mesenchymal transition in hepatocellular carcinoma. Oncology Letters. 2017;14(5):5899-905. doi:10.3892/ol.2017.6961.

45. Liu X, Yang L, Tu J, et al. MicroRNA-526b servers as a prognostic factor and exhibits tumor suppressive property by targeting Sirtuin 7 in hepatocellular carcinoma. Oncotarget. 2017;8(50):87737-49. doi:10.18632/oncotarget.21209.

46. Kim E, Kim D, Lee JS, Yoe J, Park J, Kim CJ, et al. Capicua suppresses hepatocellular carcinoma progression by controlling the ETV4-MMP1 axis. Hepatology. 2018 Jun;67(6):2287-301. doi:10.1002/hep.29738.

47. Yu CL, Yu YL, Yang SF, Hsu CE, Lin CL, Hsieh YH, Chiou HL. Praeruptorin A reduces metastasis of human hepatocellular carcinoma cells by targeting ERK/MMP1 signaling pathway. Environ Toxicol. 2021 Apr;36(4):540-9. doi:10.1002/tox.23059.

48. Cabrita R, Lauss M, Sanna A, Donia M, Skaarup Larsen M, Mitra S, et al. Tertiary lymphoid structures improve immunotherapy and survival in melanoma. Nature. 2020 Jan;577(7791):561-565. doi: 10.1038/s41586-019-1914-8. Epub 2020 Jan 15. Erratum in: Nature. 2020 Apr;580(7801):E1.

49. Helmink BA, Reddy SM, Gao J, Zhang S, Basar R, Thakur R, et al. B cells and tertiary lymphoid structures promote immunotherapy response. Nature. 2020 Jan;577(7791):549-555. doi: 10.1038/s41586-019-1922-8. Epub 2020 Jan 15.

50. Zhao S, Yu M. Identification of MMP1 as a Potential Prognostic Biomarker and Correlating with Immune Infiltrates in Cervical Squamous Cell Carcinoma. DNA Cell Biol. 2020 Feb;39(2):255-72. doi:10.1089/dna.2019.5129.

51. Eiro N, Cid S, Aguado N, Fraile M, de Pablo N, Fernández B, Domínguez F, González LO, Vizoso FJ. MMP1 and MMP11 Expression in Peripheral Blood Mononuclear Cells upon Their Interaction with Breast Cancer Cells and Fibroblasts. Int J Mol Sci. 2020 Dec 31;22(1):371. doi: 10.3390/ijms22010371.

52. Geng $X$, Chen $C$, Huang $Y$, Hou J. The prognostic value and potential mechanism of Matrix Metalloproteinases among Prostate Cancer. Int J Med Sci. 2020 Jun 21;17(11):1550-1560. doi: 10.7150/ijms.46780.

53. Wculek SK, Cueto FJ, Mujal AM, Melero I, Krummel MF, Sancho D. Dendritic cells in cancer immunology and immunotherapy. Nat Rev Immunol. 2020 Jan;20(1):7-24. doi:10.1038/s41577-019-0210-z.

54. Zhang J, Endres S, Kobold S. Enhancing tumor T cell infiltration to enable cancer immunotherapy. Immunotherapy. 2019 Feb;11(3):201-13. doi:10.2217/imt-2018-0111.

55. Laviron M, Boissonnas A. Ontogeny of Tumor-Associated Macrophages. Front Immunol. 2019 Jul;31:10:1799. doi:10.3389/fimmu.2019.01799.

56. Altorki NK, Markowitz GJ, Gao D, Port JL, Saxena A, Stiles B, et al. The lung microenvironment: an important regulator of tumour growth and metastasis. Nat Rev Cancer. 2019 Jan;19(1):9-31. doi: 10.1038/s41568-018-0081-9.

\section{Tables}


Table 1

Correlation of MMP1 expression and prognosis in hepatocellular carcinoma patients with different clinicopathological factors via Kaplan-Meier plotter.

\begin{tabular}{|c|c|c|c|c|c|c|c|c|c|c|c|c|c|}
\hline \multirow[t]{2}{*}{$\begin{array}{l}\text { Clinicopathological } \\
\text { factors }\end{array}$} & \multirow[t]{2}{*}{ Subgroup } & \multicolumn{3}{|c|}{$\begin{array}{l}\text { Overall survival } \\
(n=364)\end{array}$} & \multicolumn{3}{|c|}{$\begin{array}{l}\text { Progression-free survival } \\
(n=366)\end{array}$} & \multicolumn{3}{|c|}{$\begin{array}{l}\text { Relapse-free survival } \\
(n=313)\end{array}$} & \multicolumn{3}{|c|}{$\begin{array}{l}\text { Disease specific surviva } \\
(n=357)\end{array}$} \\
\hline & & No. & $\begin{array}{l}\text { Hazard } \\
\text { ratio }\end{array}$ & $\begin{array}{l}P \\
\text { value }\end{array}$ & No. & $\begin{array}{l}\text { Hazard } \\
\text { ratio }\end{array}$ & $\begin{array}{l}P \\
\text { value }\end{array}$ & No. & $\begin{array}{l}\text { Hazard } \\
\text { ratio }\end{array}$ & $\begin{array}{l}\mathrm{P} \\
\text { value }\end{array}$ & No. & $\begin{array}{l}\text { Hazard } \\
\text { ratio }\end{array}$ & $\begin{array}{l}\mathrm{P} \\
\text { va }\end{array}$ \\
\hline \multirow[t]{4}{*}{ Stage } & Stage 1 & 170 & $\begin{array}{l}2.25(1.21- \\
4.19)\end{array}$ & 0.0084 & 170 & $\begin{array}{l}2.04(1.24- \\
3.35)\end{array}$ & 0.0043 & 153 & $\begin{array}{l}2.08(1.2- \\
3.6)\end{array}$ & 0.0073 & 167 & $\begin{array}{l}0.6(0.25- \\
1.44)\end{array}$ & $0 . \AA$ \\
\hline & Stage 2 & 83 & $\begin{array}{l}1.76(0.81- \\
3.81)\end{array}$ & 0.15 & 84 & $\begin{array}{l}1.56(0.86- \\
2.84)\end{array}$ & 0.14 & 74 & $\begin{array}{l}0.61(0.26- \\
1.43)\end{array}$ & 0.25 & 82 & $\begin{array}{l}\text { 3.4e08(NA- } \\
\text { NA) }\end{array}$ & 0.1 \\
\hline & Stage 3 & 83 & $\begin{array}{l}2.39(1.30- \\
4.38)\end{array}$ & 0.0037 & 83 & $\begin{array}{l}1.77(0.98- \\
3.2)\end{array}$ & 0.055 & 68 & $\begin{array}{l}1.83(0.96- \\
3.5)\end{array}$ & 0.063 & 81 & $\begin{array}{l}3.35(1.62- \\
6.93)\end{array}$ & $\begin{array}{l}5.1 \\
04\end{array}$ \\
\hline & Stage 4 & 4 & NA & NA & 5 & NA & NA & 0 & NA & NA & 3 & NA & N $/$ \\
\hline \multirow[t]{4}{*}{ Grade } & Grade 1 & 55 & $\begin{array}{l}3.2(1.15- \\
8.91)\end{array}$ & 0.02 & 55 & $\begin{array}{l}3.53(1.54- \\
8.08)\end{array}$ & 0.0017 & 45 & $\begin{array}{l}7.81(1.03- \\
59.34)\end{array}$ & 0.019 & 55 & $\begin{array}{l}3.18(0.89- \\
11.32)\end{array}$ & 0.1 \\
\hline & Grade 2 & 174 & $\begin{array}{l}1.98(1.18- \\
3.33)\end{array}$ & 0.0082 & 175 & $\begin{array}{l}2.57(1.66- \\
3.98)\end{array}$ & $\begin{array}{l}1.2 e- \\
05\end{array}$ & 147 & $\begin{array}{l}2.39(1.4- \\
4.06)\end{array}$ & $\begin{array}{l}9.3 e- \\
04\end{array}$ & 169 & $\begin{array}{l}3.14(1.54- \\
6.39)\end{array}$ & $\begin{array}{l}8 . ! \\
04\end{array}$ \\
\hline & Grade 3 & 118 & $\begin{array}{l}2.41(1.32- \\
4.39)\end{array}$ & 0.003 & 119 & $\begin{array}{l}1.58(0.95- \\
2.63)\end{array}$ & 0.073 & 106 & $\begin{array}{l}0.65(0.38- \\
1.11)\end{array}$ & 0.11 & 116 & $\begin{array}{l}2.55(1.2- \\
5.43)\end{array}$ & 0.1 \\
\hline & Grade 4 & 12 & NA & NA & 12 & NA & NA & 11 & NA & NA & 12 & NA & N $/$ \\
\hline \multirow[t]{4}{*}{ AJCC_T } & $\mathrm{T} 1$ & 180 & $\begin{array}{l}2.09(1.16- \\
3.76)\end{array}$ & 0.012 & 180 & $\begin{array}{l}1.99(1.23- \\
3.23)\end{array}$ & 0.0045 & 160 & $\begin{array}{l}2.06(1.21- \\
3.51)\end{array}$ & 0.0068 & 177 & $\begin{array}{l}2.06(0.7- \\
6.04)\end{array}$ & 0. \\
\hline & T2 & 90 & $\begin{array}{l}1.6(0.78- \\
3.28)\end{array}$ & 0.2 & 92 & $\begin{array}{l}1.36(0.78- \\
2.37)\end{array}$ & 0.27 & 79 & $\begin{array}{l}0.54(0.23- \\
1.24)\end{array}$ & 0.14 & 89 & $\begin{array}{l}3.81(0.87- \\
16.7)\end{array}$ & 0.1 \\
\hline & T3 & 78 & $\begin{array}{l}3.05(1.64- \\
5.69)\end{array}$ & $\begin{array}{l}2.3 e- \\
04\end{array}$ & 78 & $1.8(1-3.24)$ & 0.048 & 65 & $\begin{array}{l}1.76(0.9- \\
3.44)\end{array}$ & 0.097 & 75 & $\begin{array}{l}3.82(1.79- \\
8.13)\end{array}$ & $2 \epsilon$ \\
\hline & $\mathrm{T} 4$ & 13 & NA & NA & 13 & NA & NA & 6 & NA & NA & 13 & NA & $\mathrm{N} /$ \\
\hline \multirow[t]{2}{*}{ Gender } & Female & 118 & $\begin{array}{l}1.71(0.86- \\
3.43)\end{array}$ & 0.12 & 120 & $\begin{array}{l}2.25(1.34- \\
3.77)\end{array}$ & 0.0016 & 105 & $\begin{array}{l}3.02(1.45- \\
6.28)\end{array}$ & 0.0019 & 116 & $\begin{array}{l}2.99(1.04- \\
8.57)\end{array}$ & 0.1 \\
\hline & Male & 246 & $\begin{array}{l}2.9(1.86- \\
4.52)\end{array}$ & $\begin{array}{l}8.3 e- \\
07\end{array}$ & 246 & $\begin{array}{l}1.86(1.29- \\
2.67)\end{array}$ & $\begin{array}{l}6.8 e- \\
04\end{array}$ & 208 & $\begin{array}{l}1.75(1.17- \\
2.61)\end{array}$ & 0.0057 & 241 & $\begin{array}{l}3.4(1.92- \\
6.02)\end{array}$ & $\begin{array}{l}7.1 \\
06\end{array}$ \\
\hline \multirow[t]{3}{*}{ Vascular invasion } & None & 203 & $\begin{array}{l}2.09(1.24- \\
3.55)\end{array}$ & 0.005 & 204 & $\begin{array}{l}1.77(1.13- \\
2.77)\end{array}$ & 0.011 & 175 & $\begin{array}{l}1.84(1.08- \\
3.15)\end{array}$ & 0.023 & 200 & $\begin{array}{l}2.16(1.04- \\
4.5)\end{array}$ & 0.1 \\
\hline & micro & 90 & $\begin{array}{l}1.92(0.87- \\
4.22)\end{array}$ & 0.098 & 91 & $\begin{array}{l}1.93(1.09- \\
3.4)\end{array}$ & 0.022 & 81 & $\begin{array}{l}1.69(0.9- \\
3.17)\end{array}$ & 0.1 & 88 & $\begin{array}{l}4.03(1.35- \\
11.99)\end{array}$ & 0.1 \\
\hline & macro & 16 & NA & NA & 16 & NA & NA & 14 & NA & NA & 14 & NA & $\mathrm{N} /$ \\
\hline \multirow[t]{2}{*}{ Race } & White & 181 & $\begin{array}{l}1.51(0.93- \\
2.45)\end{array}$ & 0.091 & 183 & $\begin{array}{l}1.8(1.21- \\
2.67)\end{array}$ & 0.0033 & 147 & $\begin{array}{l}1.82(1.12- \\
2.97)\end{array}$ & 0.015 & 177 & $\begin{array}{l}2.86(1.21- \\
6.73)\end{array}$ & 0.1 \\
\hline & Asian & 155 & $\begin{array}{l}3.88(2.14- \\
7.06)\end{array}$ & $\begin{array}{l}1.7 e- \\
06\end{array}$ & 155 & $\begin{array}{l}2.28(1.41- \\
3.68)\end{array}$ & $\begin{array}{l}5.4 \mathrm{e}- \\
04\end{array}$ & 143 & $\begin{array}{l}2.11(1.26- \\
3.52)\end{array}$ & 0.0038 & 152 & $\begin{array}{l}4.27(1.93- \\
9.46)\end{array}$ & $1 e$ \\
\hline $\begin{array}{l}\text { Sorafenib } \\
\text { treatment }\end{array}$ & treated & 29 & $\begin{array}{l}5.22(1.09- \\
25.13)\end{array}$ & 0.026 & 30 & $\begin{array}{l}1.54(0.67- \\
3.58)\end{array}$ & 0.31 & 22 & $\begin{array}{l}1.56(0.61- \\
3.99)\end{array}$ & 0.35 & 29 & $\begin{array}{l}5.22(1.09- \\
25.13)\end{array}$ & 0.1 \\
\hline \multirow[t]{2}{*}{$\begin{array}{l}\text { Alcohol } \\
\text { consumption }\end{array}$} & Yes & 115 & $\begin{array}{l}1.56(0.82- \\
3)\end{array}$ & 0.17 & 115 & $\begin{array}{l}2.32(1.38- \\
3.89)\end{array}$ & 0.0011 & 98 & $\begin{array}{l}2.38(1.31- \\
4.3)\end{array}$ & 0.0032 & 115 & $\begin{array}{l}1.9(0.91- \\
3.94)\end{array}$ & 0.1 \\
\hline & none & 202 & $\begin{array}{l}2.59(1.47- \\
4.58)\end{array}$ & $\begin{array}{l}6.7 e- \\
04\end{array}$ & 204 & $\begin{array}{l}1.93(1.28- \\
2.9)\end{array}$ & 0.0013 & 182 & $\begin{array}{l}1.91(1.14- \\
3.21)\end{array}$ & 0.013 & 197 & $\begin{array}{l}4.1(1.72- \\
9.78)\end{array}$ & $\begin{array}{l}5.1 \\
04\end{array}$ \\
\hline \multirow[t]{2}{*}{ Hepatitis virus } & Yes & 150 & $\begin{array}{l}3.33(1.73- \\
6.39)\end{array}$ & $\begin{array}{l}1.3 e- \\
04\end{array}$ & 152 & $\begin{array}{l}2.02(1.27- \\
3.22)\end{array}$ & 0.0026 & 138 & $\begin{array}{l}1.75(1.06- \\
2.87)\end{array}$ & 0.026 & 149 & $\begin{array}{l}3.54(1.55- \\
8.08)\end{array}$ & 0.1 \\
\hline & none & 167 & $\begin{array}{l}1.76(1.1- \\
2.8)\end{array}$ & 0.017 & 167 & $\begin{array}{l}2.19(1.41- \\
3.39)\end{array}$ & $\begin{array}{l}3.3 e- \\
04\end{array}$ & 142 & $\begin{array}{l}1.99(1.2- \\
3.31)\end{array}$ & 0.0066 & 163 & $\begin{array}{l}2.41(1.31- \\
4.44)\end{array}$ & 0.1 \\
\hline
\end{tabular}

AJCC,American Joint Committee on Cancer; NA, not available data; $P$ value less than 0.05 is shown in bold. 
Table 2

Correlation analysis between MMP1 and related genes and markers of immune cells in hepatocellular carcinoma via TIMER.

\begin{tabular}{|c|c|c|c|c|c|}
\hline \multirow[t]{2}{*}{ Description } & \multirow[t]{2}{*}{ Gene markers } & \multicolumn{2}{|l|}{ None } & \multicolumn{2}{|l|}{ Purity } \\
\hline & & correlation & $p$ & correlation & p \\
\hline \multirow[t]{2}{*}{ B cell } & $C D 19$ & 0.129 & $1.31 \mathrm{e}-02$ & 0.147 & $6.35 \mathrm{e}-03$ \\
\hline & $C D 79 A$ & 0.114 & $2.81 e-02$ & 0.155 & $3.8 \mathrm{e}-03$ \\
\hline \multirow[t]{2}{*}{ CD8 + T cell } & $C D 8 A$ & 0.159 & $2.19 e-03$ & 0.209 & $9.55 e-05$ \\
\hline & $C D 8 B$ & 0.198 & $1.28 \mathrm{e}-04$ & 0.239 & $7.09 \mathrm{e}-06$ \\
\hline \multirow[t]{2}{*}{ Monocyte } & $C D 86$ & 0.285 & $2.18 \mathrm{e}-08$ & 0.377 & $4.03 e-13$ \\
\hline & CD115(CSF1R) & 0.209 & $4.83 e-05$ & 0.29 & $4.06 \mathrm{e}-08$ \\
\hline \multirow[t]{3}{*}{ TAM } & CCL2 & 0.154 & $2.87 e-03$ & 0.189 & $4.15 e-04$ \\
\hline & $C D 68$ & 0.267 & $1.69 \mathrm{e}-07$ & 0.325 & $6.6 e-10$ \\
\hline & IL 10 & 0.248 & $1.38 \mathrm{e}-06$ & 0.326 & $5.7 e-10$ \\
\hline \multirow[t]{3}{*}{ M1 Macrophage } & IRF5 & 0.162 & $1.77 e-03$ & 0.168 & $1.69 \mathrm{e}-03$ \\
\hline & INOS(NOS2) & 0.013 & $8.02-01$ & 0.025 & $6.46 e-01$ \\
\hline & COX2(PTGS2) & 0.15 & $3.84 \mathrm{e}-03$ & 0.201 & $1.65 e-04$ \\
\hline \multirow[t]{3}{*}{ M2 Macrophage } & CD163 & 0.092 & $7.75 e-02$ & 0.158 & $3.18 \mathrm{e}-03$ \\
\hline & VSIG4 & 0.125 & $1.63 \mathrm{e}-02$ & 0.173 & $1.25 e-03$ \\
\hline & $M S 4 A 4 A$ & 0.123 & $1.74 \mathrm{e}-02$ & 0.196 & $2.51 \mathrm{e}-04$ \\
\hline \multirow[t]{3}{*}{ Neutrophils } & CD66b(CEACAM8) & 0.068 & $1.92 \mathrm{e}-01$ & 0.086 & $1.1 \mathrm{e}-01$ \\
\hline & CD11b(ITGAM) & 0.317 & $4.31 \mathrm{e}-10$ & 0.364 & $2.84 e-12$ \\
\hline & CCR7 & 0.019 & $7.12 \mathrm{e}-01$ & 0.065 & $2.25 \mathrm{e}-01$ \\
\hline \multirow[t]{7}{*}{ Dendritic cell } & $H L A-D P B 1$ & 0.173 & $8.09 e-04$ & 0.227 & $2.11 \mathrm{e}-05$ \\
\hline & $H L A-D Q B 1$ & 0.184 & $3.8 e-04$ & 0.237 & $8.36 \mathrm{e}-06$ \\
\hline & $H L A-D R A$ & 0.191 & $2.15 \mathrm{e}-04$ & 0.251 & $2.37 e-06$ \\
\hline & $H L A-D P A 1$ & 0.16 & $2.02 \mathrm{e}-03$ & 0.219 & $4.02 e-05$ \\
\hline & $C D 1 c(B D C A-1)$ & 0.087 & $9.4 \mathrm{e}-02$ & 0.12 & $2.57 \mathrm{e}-02$ \\
\hline & $N R P 1$ & 0.218 & $2.26 \mathrm{e}-05$ & 0.218 & $4.29 \mathrm{e}-05$ \\
\hline & ITGAX & 0.321 & $2.38 e-10$ & 0.419 & $4.38 \mathrm{e}-16$ \\
\hline \multirow[t]{6}{*}{ Tregs } & FOXP3 & 0.123 & $1.82 \mathrm{e}-02$ & 0.172 & $1.33 e-03$ \\
\hline & CCR8 & 0.254 & $7.07 e-07$ & 0.311 & $3.53 \mathrm{e}-09$ \\
\hline & STAT5B & 0.094 & $7.2 \mathrm{e}-02$ & 0.099 & $6.53 e-02$ \\
\hline & TGFB1 & 0.24 & $2.81 \mathrm{e}-06$ & 0.277 & $1.67 \mathrm{e}-07$ \\
\hline & CD25(IL2RA) & 0.27 & $1.26 \mathrm{e}-07$ & 0.356 & $1.02 \mathrm{e}-11$ \\
\hline & $C D 4$ & 0.186 & $3.21 \mathrm{e}-04$ & 0.247 & $3.34 \mathrm{e}-06$ \\
\hline \multirow[t]{6}{*}{ T cell exhaustion } & $P D-1(P D C D 1)$ & 0.219 & $2.17 \mathrm{e}-05$ & 0.268 & $4.55 \mathrm{e}-07$ \\
\hline & CTLA4 & 0.326 & $1.26 \mathrm{e}-10$ & 0.386 & $1.02 e-13$ \\
\hline & $L A G 3$ & 0.179 & $5.32 \mathrm{e}-04$ & 0.2 & $1.86 \mathrm{e}-04$ \\
\hline & TIM-3(HAVCR2) & 0.33 & $6.72 \mathrm{e}-11$ & 0.436 & $1.8 \mathrm{e}-17$ \\
\hline & $B T L A$ & 0.065 & $2.12 \mathrm{e}-01$ & 0.121 & $2.49 \mathrm{e}-02$ \\
\hline & $T I G I T$ & 0.283 & $2.86 \mathrm{e}-08$ & 0.348 & $3.14 \mathrm{e}-11$ \\
\hline
\end{tabular}




\begin{tabular}{|c|c|c|c|c|c|}
\hline \multirow[t]{2}{*}{ Description } & \multirow[t]{2}{*}{ Gene markers } & \multicolumn{2}{|l|}{ None } & \multicolumn{2}{|l|}{ Purity } \\
\hline & & correlation & $p$ & correlation & $p$ \\
\hline & $G Z M B$ & 0.178 & $5.75 \mathrm{e}-04$ & 0.206 & $1.12 \mathrm{e}-04$ \\
\hline
\end{tabular}

TAM, tumor-associated macrophage; Cor, R value of Spearman's correlation; None, correlation without adjustment. Purity, correlation adjusted by purity. Bold values indicate $p<0.05$;

\section{Figures}

A

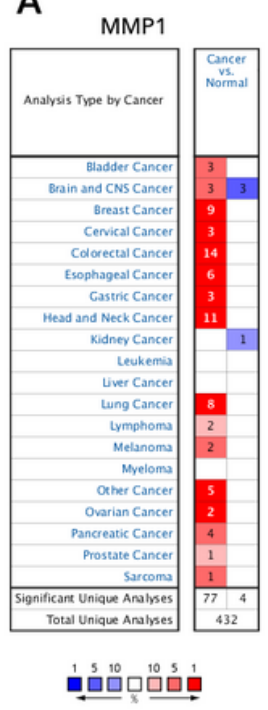

Gene rank percentile (\%)
B
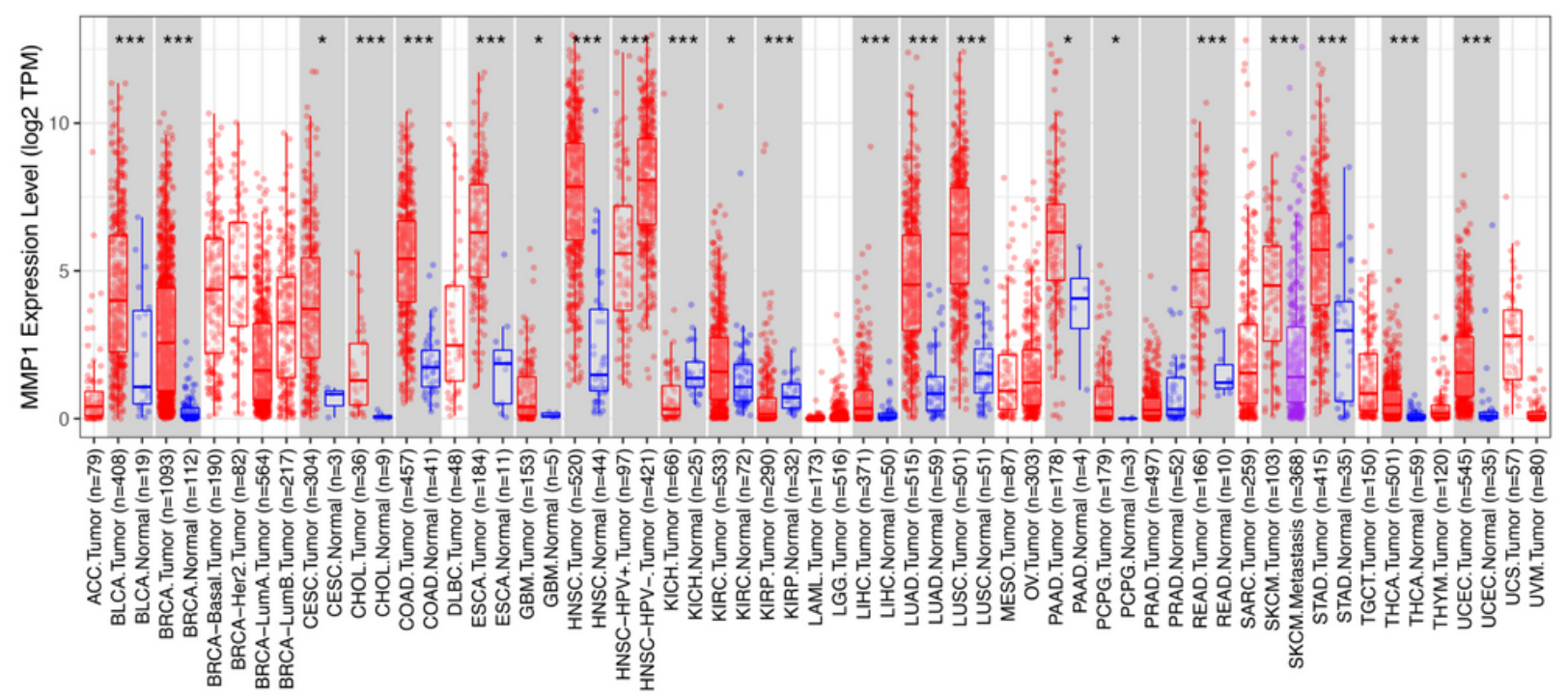

Figure 1

MMP1 expression levels in tumor and normal tissues of various cancers. (A) High expression levels of MMP1 in various cancer tissues compared with adjacent normal tissue using Oncomine analysis. (B) Comparison of MMP1 expression levels in different tumor and normal tissues via TIMER database. ${ }^{*} \mathrm{P}<0.05,{ }^{* *} \mathrm{P}<0.01, * * * \mathrm{P}<0.001$. 


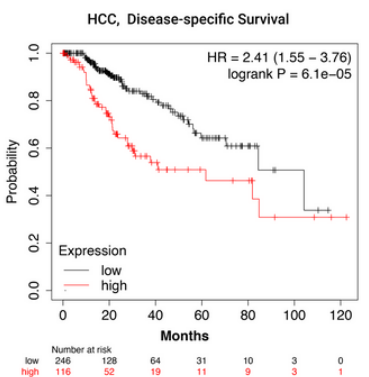

C

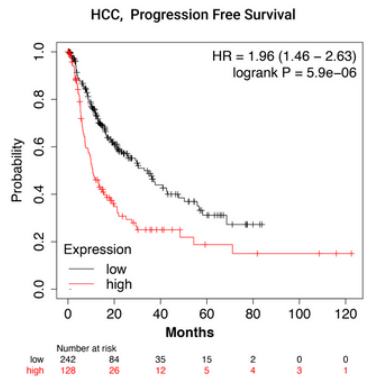

E

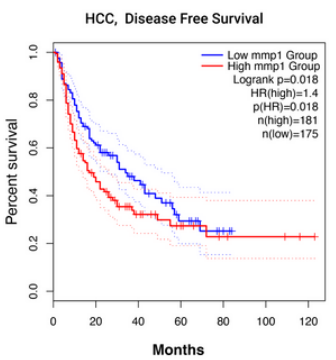

B

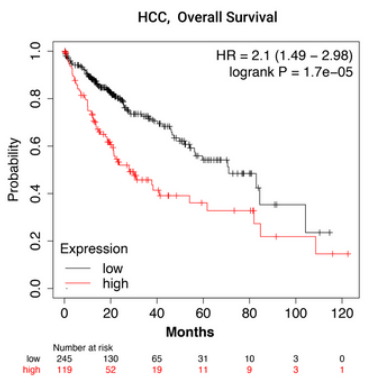

D

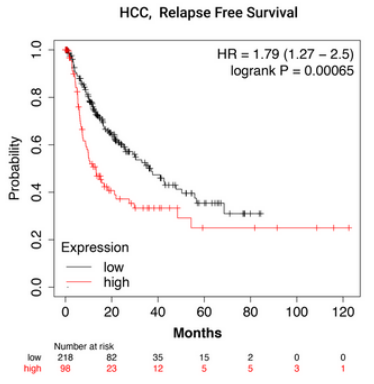

F

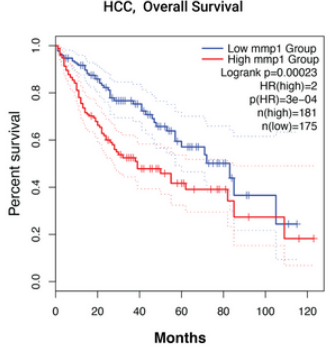

\section{Figure 2}

Prognostic potential of MMP1 expression in HCC patients via Kaplan-Meier plotter analysis (A-D) and GEPIA database (E-F). (A) Disease-specific survival (DSS), $n=357$; (B) Overall survival (OS), $n=364$; (C) Progression Free Survival (PFS), $n=366$. (D) Relapse free survival, $n=313$; (E) Disease-free survival (DFS) of HCC cohorts verified with GEPIA database, $n=356$; (F) OS of HCC cohorts verified with GEPIA database, $n=356$. 
A Breast Cancer
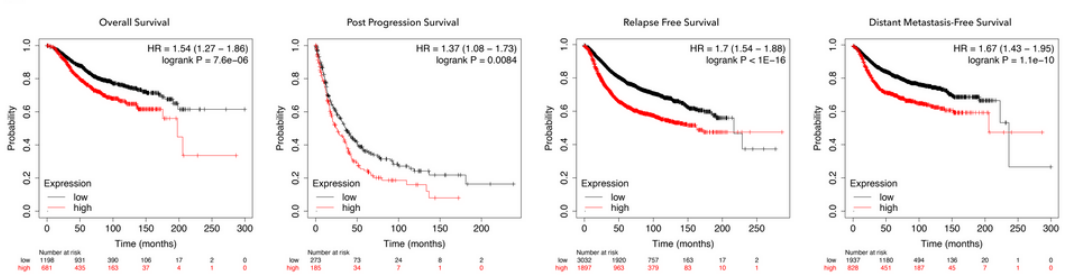

B

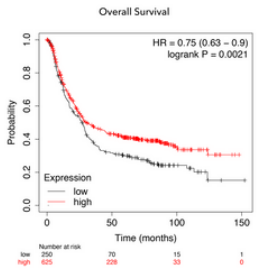

Gastric Cancer
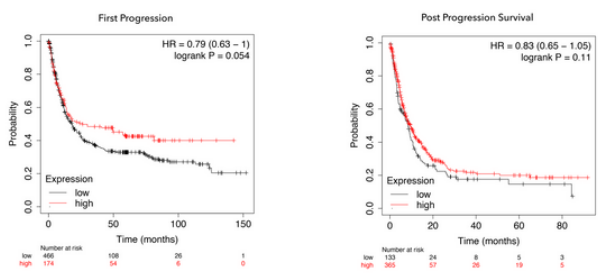

C
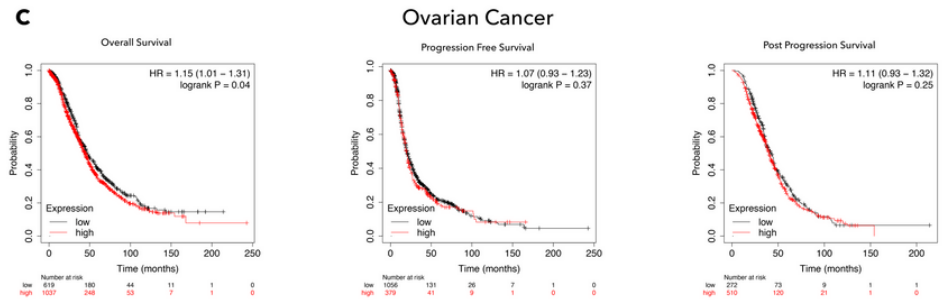

D
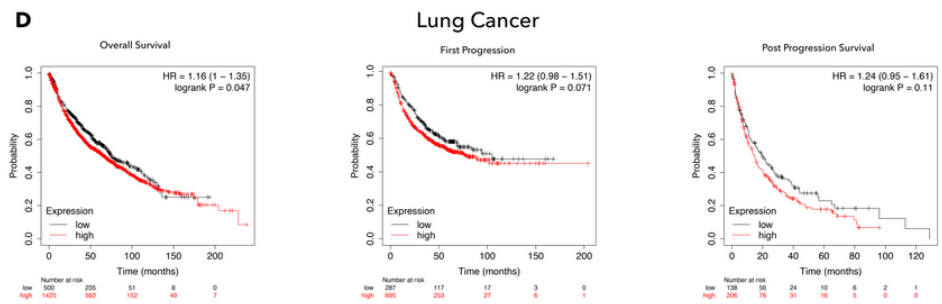

\section{Figure 3}

Prognostic potential of MMP1 expression in HCC patients via Kaplan-Meier plotter analysis (A-D) and GEPIA database (E-F). (A) Disease-specific survival (DSS), $n=357$; (B) Overall survival (OS), $n=364$; (C) Progression Free Survival (PFS), $n=366$. (D) Relapse free survival, $n=313$; (E) Disease-free survival (DFS) of HCC cohorts verified with GEPIA database, $n=356$; (F) OS of HCC cohorts verified with GEPIA database, $n=356$. 


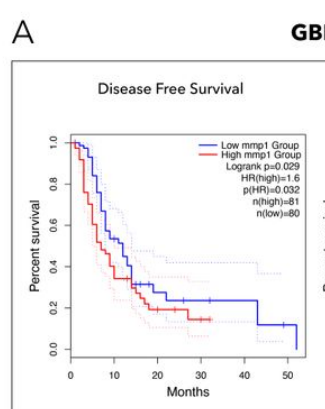

GBM

B

HNSC
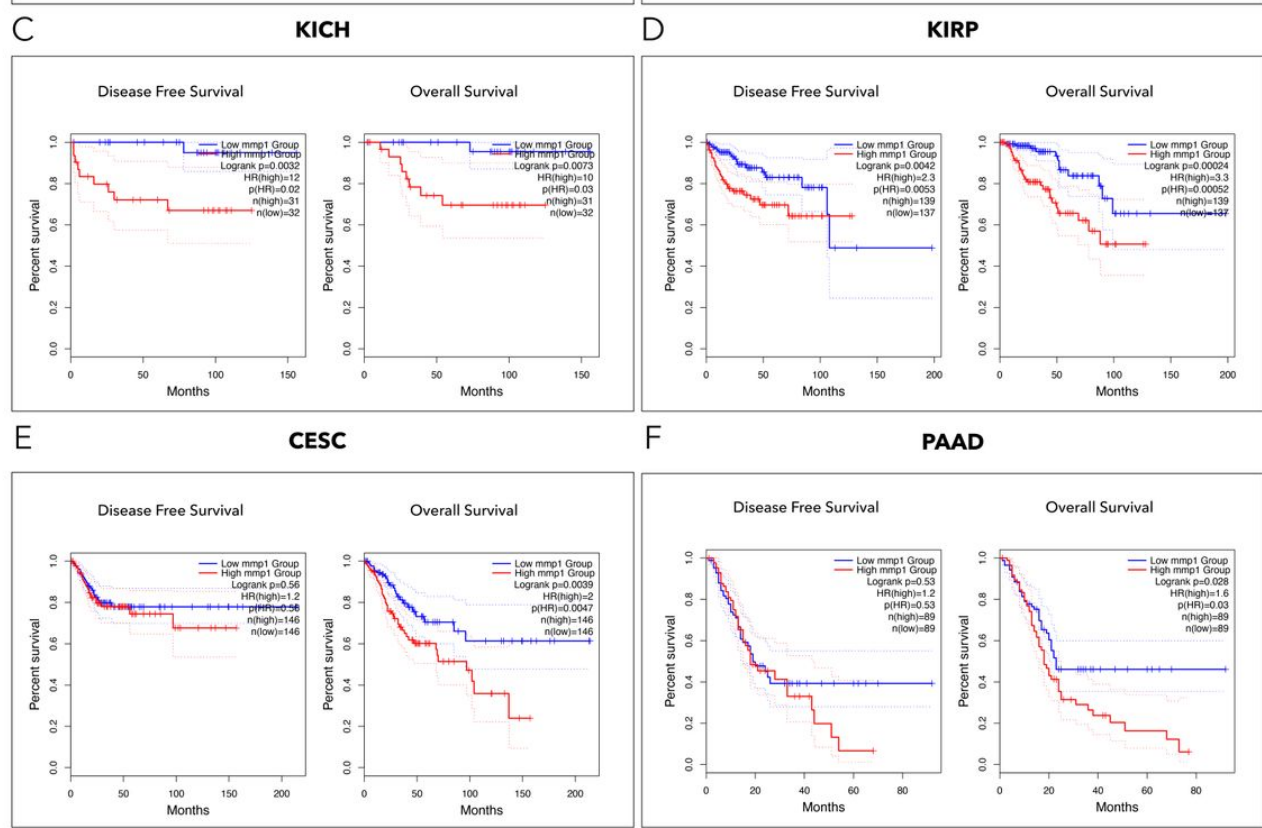

\section{Figure 4}

Interrelationship evaluation between MMP1 expression and prognostic potential in various carcinomas via GEPIA database. (A) DFS ( $\mathrm{n}=161)$ and OS ( $\mathrm{n}=161$ ) survival curves in glioblastoma multiforme (GBM). (B) DFS ( $n=518)$ and OS $(n=518)$ survival curves in head and neck squamous cell carcinoma (HNSC). (C) DFS $(n=63)$ and OS $(n=63)$ survival curves in kidney chromophobe $(K I C H)$. (D) DFS $(n=276)$ and OS $(n=276)$ survival curves in kidney renal papillary cell carcinoma (KIRP). (E) DFS ( $n=292)$ and OS ( $n=292)$ survival curves in cervical squamous cell carcinoma and endocervical adenocarcinoma (CESC). (F) DFS $(n=178)$ and OS $(n=178)$ survival curves in pancreatic adenocarcinoma (PAAD). DFS, disease free survival; OS, overall survival. 


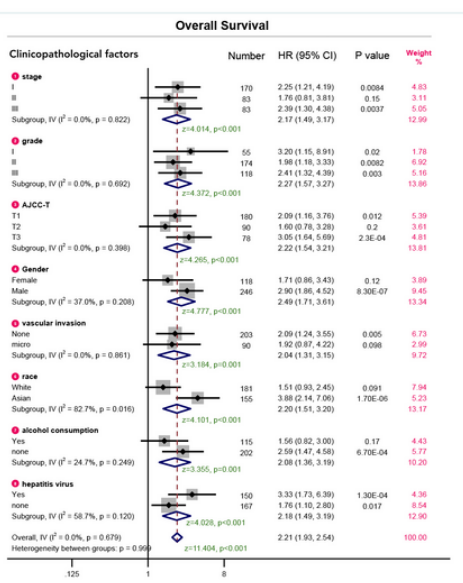

C

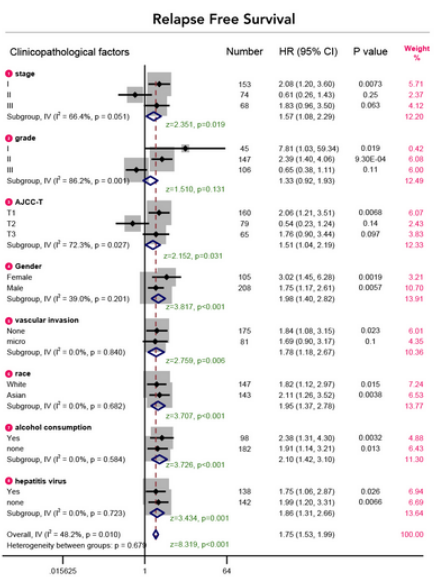

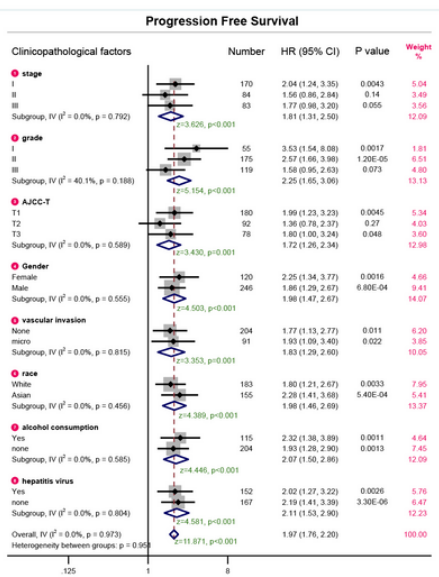

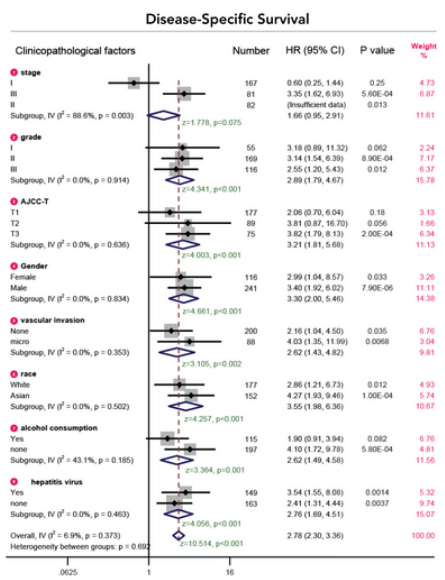

\section{Figure 5}

Correlation analysis between MMP1 expression and different clinicopathological characteristics in HCC patients. (A) cox regression analysis of OS in HCC patients. (B) cox regression analysis of PFS in HCC patients. (C) cox regression analysis of RFS in HCC patients. (D) cox regression analysis of DSS in HCC patients. OS, overall survival; PFS, progression free survival; RFS, relapse free survival; DSS, disease specific survival; HR, hazard ratio; $\mathrm{Cl}$, confidence interval.
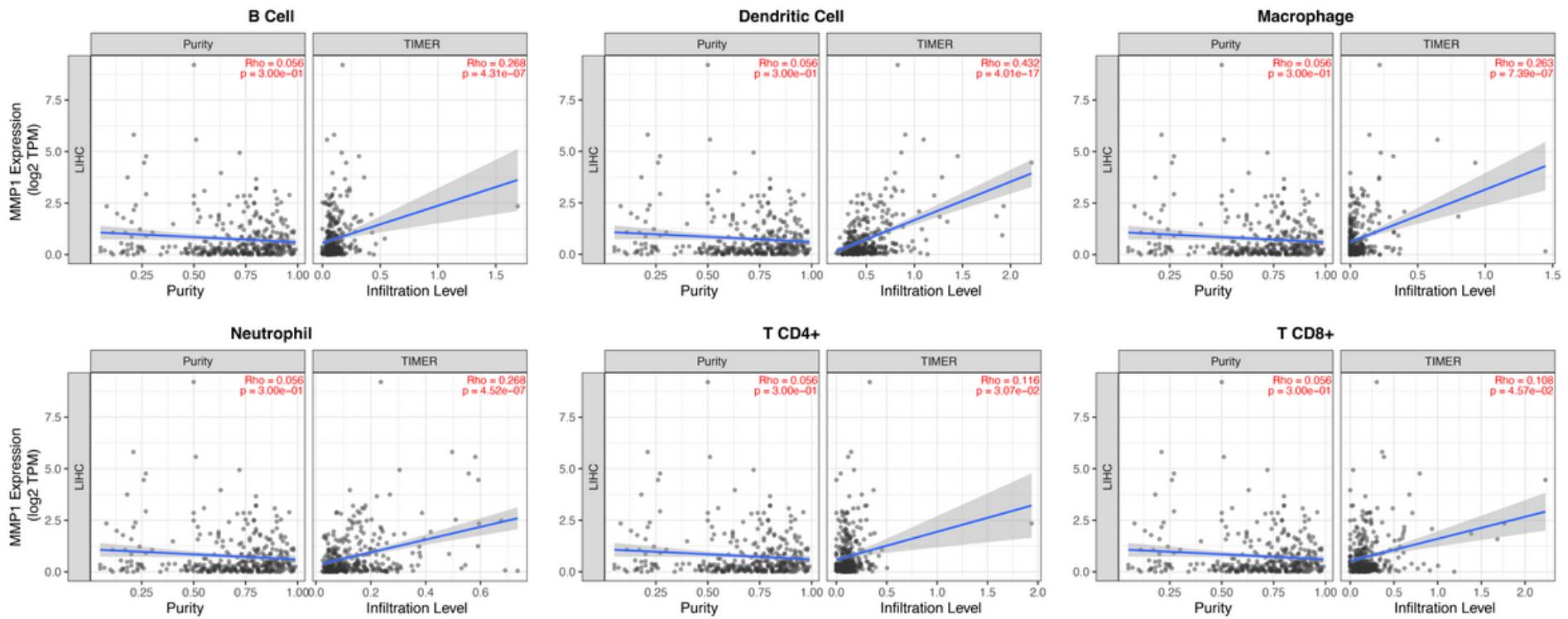

Figure 6 

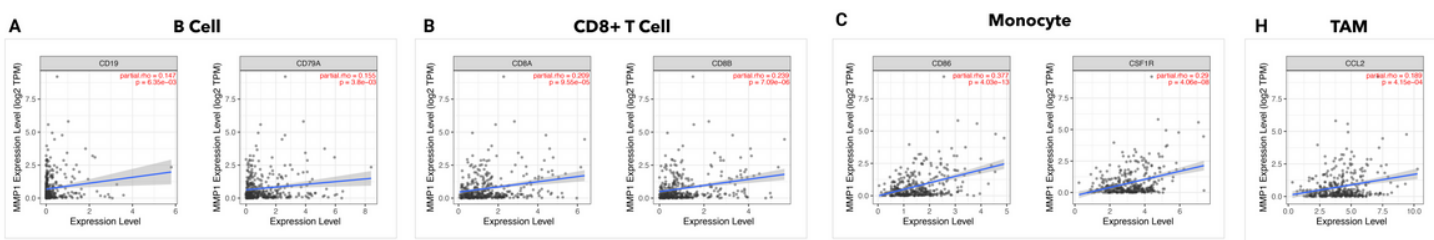
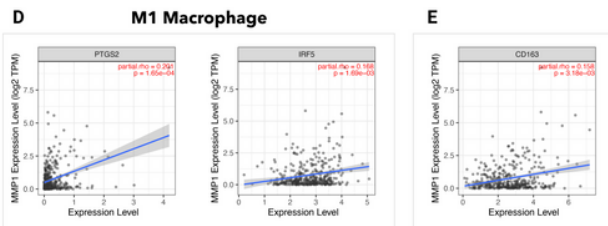

M2 Macrophage
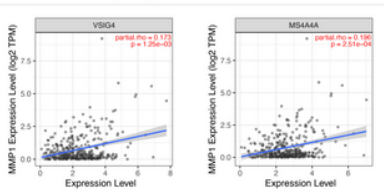

F Neutrophils
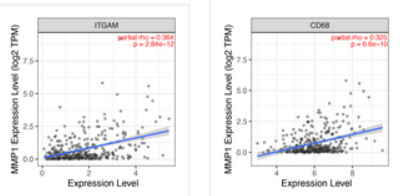

G
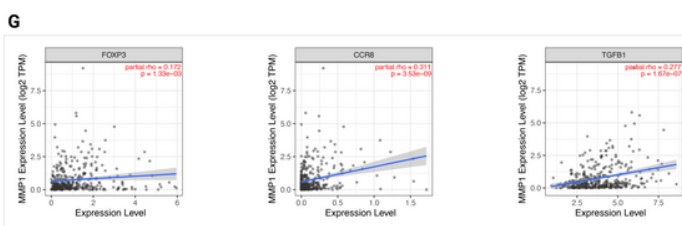

Tregs
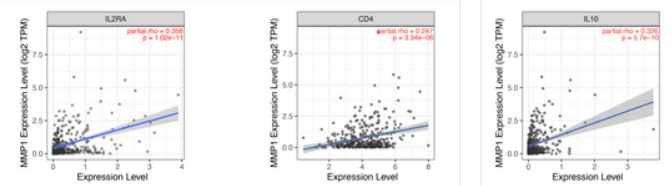

I
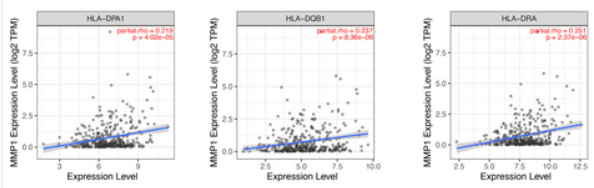

Dendritic Cell
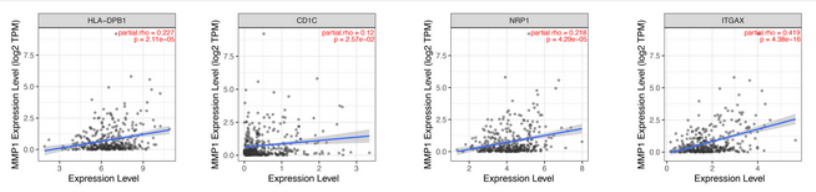

J
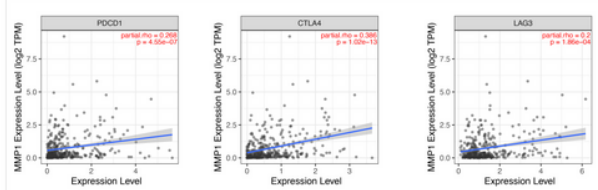

Exhausted T Cell
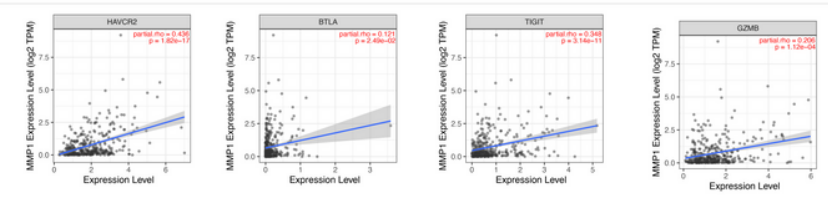

\section{Figure 7}

Analysis of the correlation between MMP1 and various TIICs' biomarker gene expression in HCC patients using the TIMER 2.0 database. Biomarkers for: (A) B Cells; (B) CD8+ T Cells; (C) monocytes; (D) M1 Macrophages; (E) M2 Macrophages; (F) Neutrophils; (G) Tregs; (H) tumor-associated macrophages (TAMs ); (I) dendritic cells and $(\mathrm{J})$ exhausted T Cells. 
A

TMB

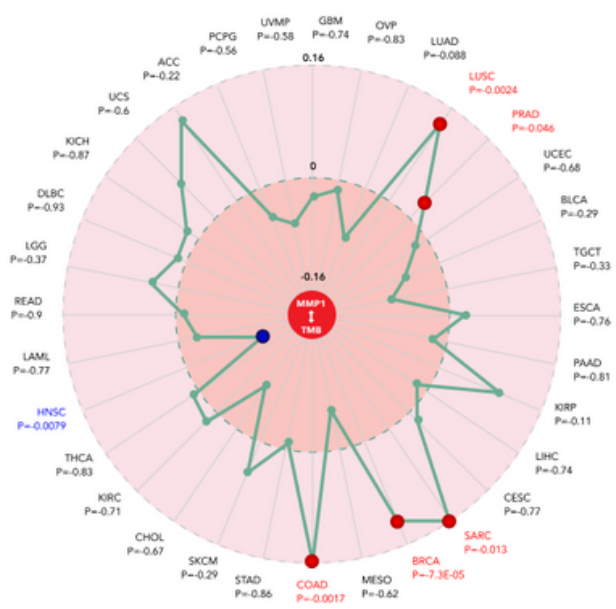

B MSI

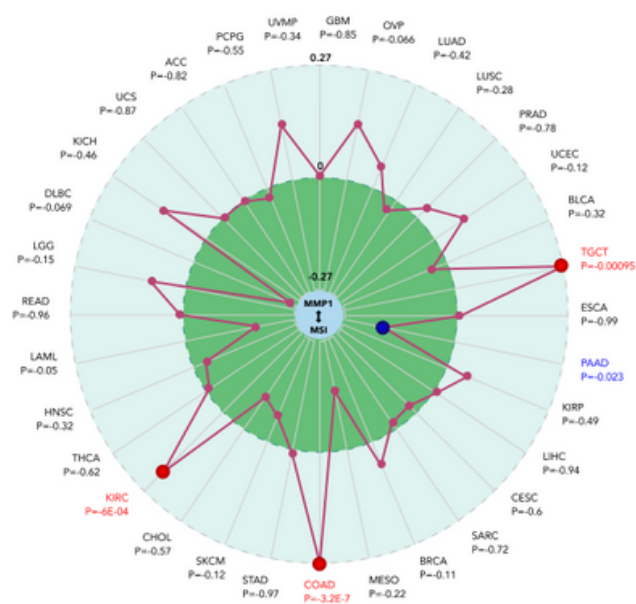

Figure 8

Correlation between MMP1 expression and tumor mutational burden (TMB) and microsatellite instability (MSI). (A) Based on the 32 types of cancers of TCGA, the relationship between MMP1 expression and TMB were evaluated. The partial correlation (cor) values of +0.16 and -0.16 were marked and $p$-values recorded. (B) Based on the same cancer types as in (A), the relationship between MMP1 expression and MSI was evaluated. Partial correlation (cor) values of +0.27 and -0.27 as well as p-values were recorded. 